University of Nebraska - Lincoln

DigitalCommons@University of Nebraska - Lincoln

$11-30-2018$

\title{
Environmental fate and microbial effects of monensin, lincomycin, and sulfamethazine residues in soil
}

\author{
Matteo D'Alessio \\ University of Nebraska-Lincoln, matteouh@gmail.com \\ Lisa M. Durso \\ USDA-ARS, Agroecosystem Management Research Unit \\ Daniel N. Miller \\ USDA-ARS, Agroecosystem Management Research Unit, dan.miller@ars.usda.gov \\ Brian Woodbury \\ USDA, U.S. Meat Animal Waste Management Center \\ Chittaranjan Ray \\ University of Nebraska-Lincoln, cray@nebraska.edu
}

See next page for additional authors

Follow this and additional works at: https://digitalcommons.unl.edu/watercenterpubs

Part of the Environmental Indicators and Impact Assessment Commons, Fresh Water Studies Commons, Hydraulic Engineering Commons, Hydrology Commons, Sustainability Commons, and the Water Resource Management Commons

D'Alessio, Matteo; Durso, Lisa M.; Miller, Daniel N.; Woodbury, Brian; Ray, Chittaranjan; and Snow, Daniel D., "Environmental fate and microbial effects of monensin, lincomycin, and sulfamethazine residues in soil" (2018). Faculty Publications from The Water Center. 50.

https://digitalcommons.unl.edu/watercenterpubs/50

This Article is brought to you for free and open access by the Water Center, The at DigitalCommons@University of Nebraska - Lincoln. It has been accepted for inclusion in Faculty Publications from The Water Center by an authorized administrator of DigitalCommons@University of Nebraska - Lincoln. 


\section{Authors}

Matteo D'Alessio, Lisa M. Durso, Daniel N. Miller, Brian Woodbury, Chittaranjan Ray, and Daniel D. Snow 


\title{
Environmental fate and microbial effects of monensin, lincomycin, and sulfamethazine residues in soil ${ }^{\text {is }}$
}

\author{
Matteo D'Alessio a, d, *, Lisa M. Durso b, Daniel N. Miller ${ }^{\mathrm{b}}$, Brian Woodbury ${ }^{\text {, }}$, \\ Chittaranjan Ray ${ }^{\mathrm{d}}$, Daniel D. Snow ${ }^{\mathrm{a}}$ \\ a University of Nebraska-Lincoln, Water Sciences Laboratory, 202 Water Sciences Laboratory, 1840 North 37th Street, Lincoln, NE, 68583-0844, USA \\ ${ }^{\mathrm{b}}$ USDA-ARS, Agroecosystem Management Research Unit, 251 Filley Hall, UNL East Campus, Lincoln, NE, 68583, USA \\ c USDA, U.S. Meat Animal Waste Management Center, Clay Center, NE, 68933, USA \\ d University of Nebraska-Lincoln, Nebraska Water Center, 2021 Transformation Drive, Suite 3220, Lincoln, NE, 68583-0979, USA
}

\section{A R T I C L E I N F O}

\section{Article history:}

Received 11 February 2018

Received in revised form

22 November 2018

Accepted 28 November 2018

Available online 30 November 2018

\section{Keywords:}

Antibiotics

Oxygen

Nitrate

Microbial communities

\begin{abstract}
A B S T R A C T
The impact of commonly-used livestock antibiotics on soil nitrogen transformations under varying redox conditions is largely unknown. Soil column incubations were conducted using three livestock antibiotics (monensin, lincomycin and sulfamethazine) to better understand the fate of the antibiotics, their effect on nitrogen transformation, and their impact on soil microbial communities under aerobic, anoxic, and denitrifying conditions. While monensin was not recovered in the effluent, lincomycin and sulfamethazine concentrations decreased slightly during transport through the columns. Sorption, and to a limited extent degradation, are likely to be the primary processes leading to antibiotic attenuation during leaching. Antibiotics also affected microbial respiration and clearly impacted nitrogen transformation. The occurrence of the three antibiotics as a mixture, as well as the occurrence of lincomycin alone affected, by inhibiting any nitrite reduction, the denitrification process. Discontinuing antibiotics additions restored microbial denitrification. Metagenomic analysis indicated that Proteobacteria, Bacteroidetes, Actinobacteria, and Chloroflexi were the predominant phyla observed throughout the study. Results suggested that episodic occurrence of antibiotics led to a temporal change in microbial community composition in the upper portion of the columns while only transient changes occurred in the lower portion. Thus, the occurrence of high concentrations of veterinary antibiotic residues could impact nitrogen cycling in soils receiving wastewater runoff or manure applications with potential longer-term microbial community changes possible at higher antibiotic concentrations.
\end{abstract}

(C) 2018 Elsevier Ltd. All rights reserved.

\section{Introduction}

Although nutrient runoff and pathogen risks associated with livestock manures have been long recognized, the environmental risks associated with incompletely metabolized pharmaceutical compounds used to treat livestock and excreted in manure were not recognized as a potential environmental issue until recently. Antibiotics have been detected in multiple agricultural sources (i.e., livestock wastewater, manure and crops fertilized with manure) (Aust et al., 2008; Bartelt-Hunt et al., 2011; Brown et al., 2006;

\footnotetext{
This paper has been recommended for acceptance by Dr. Sarah Harmon.

* Corresponding author. University of Nebraska-Lincoln, Water Sciences Laboratory, 202 Water Sciences Laboratory, 1840 North 37th Street, Lincoln, NE, 685830844, USA.

E-mail address: matteouh@gmail.com (M. D'Alessio).
}

Burkholder et al., 2007; Sim et al., 2011; Watanabe et al., 2008; Wei et al., 2011; Wei et al., 2016). Confined animal feeding operation (CAFO) may locally affect surface and groundwater quality. For example, sulfamethazine $\left(0.076-0.22 \mu \mathrm{g} \mathrm{L}^{-1}\right)$ and sulfadimethoxine $\left(0.046-0.068 \mu \mathrm{g} \mathrm{L}^{-1}\right)$ were detected in all six groundwater samples collected near a CAFO in Weiser, Idaho (Batt et al., 2006). In Nebraska, sulfamethazine, monensin, lincomycin, sulfathiazole, and sulfamerzine have been detected in samples from cattle and swine facilities as well as in agriculturally intensive watersheds (Bartelt-Hunt et al., 2011; Jaimes-Correa et al., 2015; Snow et al., 2011; Zhang et al., 2013). The activities of soil and groundwater bacteria can be impacted by residues of antibiotics (DeVries and Zhang, 2016). Mobilization of antibiotic residues through the vadose zone and into the aquifer will be subject to the different redox conditions occurring in the environment and also impacting the persistence of both the antibiotic and nitrate (Chee-Sanford 
et al., 2009).

Land applied fertilizers and manure contribute to nitrate loading in groundwater beneath agricultural areas (Exner et al., 2014) and also contribute substantially to nitrogen loading in surface water (Spalding and Exner, 1993). High concentrations of groundwater nitrate have been observed, particularly in the shallow aquifers of Nebraska (Exner et al., 2014; Exner and Spalding, 1985; Spalding and Exner, 1993). Sources of nitrate in ground water may be related to manure and chemical fertilizer application beyond crop needs (Buochard et al., 1992; Hepperly et al., 2009; Spalding and Exner, 1993). In addition, reduced forms of nitrogen present in manure (i.e., urea, organic nitrogen, and ammonium) can be mineralized and consequently oxidized to nitrate.

Recent studies have evaluated the impact of different classes of antibiotics (i.e. aminoglycoside, fluoroquinolone, sulfonamide, tetracycline, etc.) on denitrification using soil (Conkle and White, 2012; DeVries et al., 2015), sediment (Costanzo et al., 2005; Hou et al., 2014) and groundwater (Ahmad et al., 2014; Underwood et al., 2011) as media. Results from these studies showed contrasting behavior since antibiotics can have no effect (Conkle and White, 2012; Costanzo et al., 2005; Radl et al., 2015), enhance inhibition (DeVries et al., 2015), or enhance stimulation (Ding and He, 2010; Ilhan et al., 2011; Yan et al., 2013; Yin et al., 2017). Experimental conditions between these studies were different, since antibiotics were added individually (Roose-Amsaleg et al., 2013; Rosendahl et al., 2012) or as a mixture (Conkle and White, 2012; Costanzo et al., 2005; Underwood et al., 2011), their exposure period ranged between hours (Costanzo et al., 2005; Hou et al., 2014) and weeks (Kotzerke et al., 2008; Roose-Amsaleg et al., 2013; Rosendahl et al., 2012), while their concentrations were usually greater than $1 \mathrm{mg} \mathrm{L}^{-1}$ (Banerjee and D'Angelo, 2013; Kotzerke et al., 2008; Laverman et al., 2015; Radl et al., 2015). For example, sulfadiazine can stimulate or inhibit denitrification if present at low or high concentrations, respectively (DeVries et al., 2015). Short application (<4 days) of narasin can stimulate denitrification, while long application of the same ionophore antibiotic can inhibit denitrification (DeVries et al., 2015).

The objectives of this study were to determine: i) the environmental fate of three commonly occurring manure-borne veterinary antibiotics (monensin, lincomycin and sulfamethazine) in three common soil redox environments in the presence and absence of nitrate; ii) the effect to microbial respiration and denitrification; and iii) the overall impact to soil microbial communities using next generation sequencing methods. In addition, a comparison of each antibiotic and a mixture of all three to microbial denitrification at environmental concentrations were also investigated.

\section{Materials and methods}

\subsection{Chemicals}

Monensin (95\% pure), lincomycin (95\% pure), potassium nitrate $\left(\mathrm{KNO}_{3}\right)$, potassium bromide $(\mathrm{KBr})$, Optima-grade methanol (ThermoFisher, St. Louis, MO, USA), sulfachloropyridazine (SigmaAldrich, St. Louis, MO, USA), and sulfamethazine (98\% pure, MP Biomedicals, LLC, Solon, OH, USA) were used. Reagent grade deionized (DI) water (Thermo-Scientific, Waltham, MA, USA) with a resistivity of $0.182 \mathrm{M} \Omega \mathrm{m}$ (at $25^{\circ} \mathrm{C}$ ) was used. The chemical properties of the three antibiotics are listed in Table S1.

\subsection{Soil and water samples}

Disturbed soil samples were collected at the 6000-animal capacity, open-air cattle feedlot at the USDA, U.S. Meat Animal Research Center located in Clay Center, south-central Nebraska.
Detailed description of the facilities can be found elsewhere (Parker et al., 1999; Zhang et al., 2013). The soil is classified as Crete silt loam (fine, smectitic, mesic Pachic Argiustolls containing 24\% clay, $7 \%$ sand and $69 \%$ silt with $3 \%$ organic matter) (USDA, 2012). Surface soil samples were collected using a hand shovel at $5-10 \mathrm{~cm}$ beneath the surface, from an open-air feedlot at the drainage ditch immediately down-slope from the feedlot pen. Soil samples were air-dried, ground with a pestle to break the aggregates, sieved $(<2 \mathrm{~mm})$, and stored at $4{ }^{\circ} \mathrm{C}$ prior to being used. Feed water for the soil columns was collected from a runoff retention basin at the same feedlot. Surface water samples were collected approximately $1 \mathrm{~m}$ away from the bank of the basin and stored at $4{ }^{\circ} \mathrm{C}$ prior to being used.

\subsection{Experimental set-up}

Vertical flow-through columns $(5 \mathrm{~cm}$ inner diameter; $16 \mathrm{~cm}$ height) were used during the study. The columns had opaque walls to reduce the photo-degradation of the selected antibiotics. At the bottom of each column, a stainless steel wire mesh (openings: $40 \mu \mathrm{m}$; TWP, Berkeley, CA, USA) was placed to support the added soil and to prevent any potential leaching of the fine particulates. The wire cloth as well as all the different fittings and tubing used during the study were sterilized by autoclaving (STERIS, Mentor, $\mathrm{OH}, \mathrm{USA}$ ) for $30 \mathrm{~min}$ at $121^{\circ} \mathrm{C}$ and $143.4 \mathrm{kPa}$. Each column had two stainless steel sampling ports ( $5 \mu \mathrm{m}$ openings, Mott Corporation, Farmington, CT, USA) horizontally inserted through the unit wall and located 1.5 and $8 \mathrm{~cm}$ from the top.

Soil was added in increments of $5 \mathrm{~mm}$ to each column and compacted using a vortex mixer (VWR, Thorofare, NJ, USA) until the original bulk density was achieved. This process prevented the occurrence of macropores in the columns. Columns were slowly saturated from beneath to minimize air entrapment. A four channel head peristaltic pump (Cole-Parmer; Vernon Hills, IL, USA) was used to simultaneously introduce the different feed solutions to the different columns at a steady-state flow of $14 \mathrm{~cm} \mathrm{~d}^{-1}$. Each column was acclimated for $14 \mathrm{~d}$ using a mixture of filtered feedlot runoff and DI water (10:90). The feed water was autoclaved (STERIS, Mentor, OH, USA) at $121^{\circ} \mathrm{C}$ and $143.4 \mathrm{kPa}$ for $30 \mathrm{~min}$ before being used. After acclimation, a solution containing the three antibiotics (either singly or in combination $-20 \mu \mathrm{g} \mathrm{L}^{-1}$ ) and bromide tracer (100 $\mathrm{mg} \mathrm{L}^{-1}$ ) in feed water was applied for $7 \mathrm{~d}$ (referred to as "spike exposure"). After the injection of antibiotics was suspended, each column was flushed with feed water alone for approximately $30 \mathrm{~d}$ (referred to as flush-out).

The effect of oxygen-aerobic versus anoxic versus denitrifying-on antibiotic transport and transformation was investigated by performing the different simulations at a level of oxygen $>8 \mathrm{mg} \mathrm{L}^{-1}$ (aerobic), or $<2 \mathrm{mg} \mathrm{L}^{-1}$ (anoxic), or $<2 \mathrm{mg} \mathrm{L}^{-1}$ plus nitrate (denitrifying). Aerobic conditions were maintained by keeping the reservoir open to the atmosphere and bubbling air, while reducing/denitrifying conditions were obtained by keeping the reservoirs closed and by continuously purging the reservoir headspace and sparging the feed water with nitrogen (99\% purity Matheson Tri-Gas, Lincoln, NE, USA). Denitrifying conditions were obtained by continuous addition of $10 \mathrm{mM} \mathrm{KNO}_{3}$, and fresh feed water solutions were prepared three times per week in order to prevent any nitrate/nitrite transformation in the feed water and maintained at $4{ }^{\circ} \mathrm{C}$. An additional column, packed with sterile packing material and fed with sterile water, was used as control to evaluate the chemical removal versus biodegradation of the three antibiotics. The highest impact of biodegradation was expected to be under aerobic conditions, therefore the control column was run only under aerobic conditions. Feed water, column, sampling ports and fittings were sterilized by autoclaving at $121^{\circ} \mathrm{C}$ and $143.4 \mathrm{kPa}$ 
for $30 \mathrm{~min}$. Soil used as packing material, similar to the material used throughout the study, was autoclaved at $121^{\circ} \mathrm{C}$ and $143.4 \mathrm{kPa}$ for $30 \mathrm{~min}$ for three consecutive days before being used. Table S2 summarizes the environmental conditions investigated during the study.

To better understand the effects of the antibiotics on microbial community composition, a subsequent series of incubations simulating aerobic anoxic, and denitrifying environmental conditions were conducted where columns were sacrificed at specific points during the incubation. Columns were run either i) for 14 days (acclimation period), ii) for 21 days (14-day acclimation period followed by a 7 day antibiotics injection), or iii) for 54 days (14-day acclimation period, 7-day injection of antibiotics, and 33-day flushout) and then sacrificed and frozen for subsequent DNA extraction and analysis. Table S3 summarize the different experimental conditions used throughout the study, their duration, the presence or absence of antibiotics and the individual objectives.

Prior to DNA extraction, soil samples were divided into the upper $(1.5 \mathrm{~cm})$, middle $(8 \mathrm{~cm})$, and lower $(15 \mathrm{~cm})$ portion of each column and cross-sectioned into 80 quadrants of $0.5 \times 0.5 \mathrm{~cm}$. Eight quadrants were randomly sampled with a sterile spatula and mixed to provide a representative sample. An unexposed subsample of soil and feed water sample were also analyzed. Total DNA was extracted from the soil samples using the MoBio Power Soil ${ }^{\mathbb{Q}}$ DNA Isolation Kit (MoBio, Laboratories Inc, Carlsbad, CA, USA) following manufacturer's instructions. The total microbial DNA extractions were subjected to $16 \mathrm{~S}$ ribosomal RNA sequencing, using the Ion Torrent PGM sequencing platform. Sequencing was performed by Molecular Research Laboratory (Shallow Water, TX, USA) using universal eubacterial primers 515F and 806R (Dowd et al., 2008). Samples were purified using Agencourt Ampure beads (Agencourt Bioscience, MA, USA), barcodes were assigned, samples were applied to capture beads, and sequencing was performed according to manufacturer's instruction. Initial quality control measures included demuiltiplexing and denoising of flowgrams, and removal of adapters, barcodes, primers, short reads, and homopolymers. Next, sequences for individual samples were aligned, and chimeric sequences were flagged and removed from the dataset, along with amplicons classified as mitochondrial, chloroplast, archaeal, eukaryotic or unknown in origin. A secondary file was generated with consensus sequences, and this consensus sequence was used as input for a BLASTn search (Altschul et al., 1990), against a database assembled from RDP (Maidak et al., 2001) and GenBank. E-values were used to determine the best taxonomic assignments at the $>98 \%$ similarity level. Sequences were grouped by taxon, descriptive statistics on percent of each taxon present in each sample were calculated in Excel, as was the Shannon Diversity index for each sample. A list of genera containing denitrifying members (at least one confirmed denitrifier in the genus) was assembled by Zumft (1997), and a separate analysis using only these genera was performed for the samples under denitrifying conditions.

\subsection{Sampling and chemical analysis}

Influent, effluent, and port samples were collected and analyzed for major anions (chloride, sulfate, orthophosphate, nitrate, nitrite, and bromide), and selected antibiotics (lincomycin, monensin, and sulfamethazine). Samples from the two sampling ports, horizontally inserted through the external surface of each column, were collected by allowing the water to slowly flow through a valve connected to each port.

Analyses of selected antibiotics were performed using an Agilent 1260 binary high pressure liquid chromatograph (HPLC) coupled to an Agilent 6410 Triple Quadrupole mass spectrometer
(Agilent Technologies, Santa Clara, CA, USA). Antibiotics were separated using a HyPURITY C18 HPLC column $(250 \mathrm{~mm} \times 2.1 \mathrm{~mm}$ ID, $5 \mu \mathrm{m}$ particle size, Thermo-Scientific, Waltham, MA, USA) at a temperature of $50^{\circ} \mathrm{C}$. The HPLC gradient at flow rate of $0.20 \mathrm{~mL} \mathrm{~min}^{-1}$ began with 0:100 (methanol-0.01\% formic acid:water-1 $\mathrm{mM}$ ammonium citrate) held for one minute then a linear gradient to reach 80:20 over a period of two minutes and a 95:5 over a period of nine minutes, hold for 9 min before resetting (0:100) and equilibrating for five minutes. Ionization of analytes was performed with positive mode. A pseudo-molecular ion $[\mathrm{M}+\mathrm{H}]^{+}$(or $[\mathrm{M}+\mathrm{Na}]^{+}$adduct) was selected as the parent ion for fragmentation, and corresponding fragment ion(s) was selected for identification and quantitation. Fragmentor and collision energies used for each standard and analytes are given in Table S4, while statistics associated with the used methodology are given in Table S5. Samples were filtered using a Glass Microfiber syringe filter $(0.45 \mu \mathrm{m}$, Whatman, GE Healthcare Life Sciences, Pittsburgh, PA, USA) and sulfachloropyridazine, surrogate used during the study, was added. Surrogate had a recovery of $81.64 \pm 4.17 \%$. Recovery of the selected antibiotics was estimated by summing the mass removed after each column (effluent) or after the two sampling ports and dividing by the total mass injected. Major anions were measured with an ion chromatograph (ICS-90) (Dionex, Bannockburn, IL, USA) with a detection limit of $0.1 \mathrm{mg} \mathrm{L}^{-1}$.

Redox potential (Eh) in the effluent was continuously monitored using HYPNOS III logger (MVH Consult, Leiden, The Netherlands). The device incorporates a control unit, a multiplexer, storage memory and redox probes (Vorenhout et al., 2011). The redox probes consisted of a fiberglass shell, having a diameter of $8 \mathrm{~mm}$, equipped with platinum wire tips that were partially covered in the fiberglass (PaleoTerra, Amsterdam, The Netherlands), which were placed in flow-through cells.

\section{Results and discussion}

\subsection{Column redox conditions and general chemistry}

Measured effluent in one column was maintained under aerobic conditions (DO $>8 \mathrm{mg} \mathrm{L}^{-1}$, Eh between 480 and $600 \mathrm{mV}$ ), while under anoxic condition, Eh decreased to suboxic conditions $(100<\mathrm{Eh}<400 \mathrm{mV})$ during the first day and prior to reach anoxic conditions $(E h<100 \mathrm{mV}$ ) within two days. Under denitrifying conditions, Eh showed a similar but slower trend compared to the trend observed under anoxic conditions. After ten days, the column receiving $10 \mathrm{mM} \mathrm{KNO}_{3}$ maintained a denitrifying Eh consistently $<100 \mathrm{mV}$ (Fig. S1). Under aerobic, anoxic, and denitrifying conditions, effluent $\mathrm{pH}$ ranged between 7 and 8, 6.9 and 9, 7.2 and 9, respectively (Fig. S2). In the presence of denitrifying conditions, hydroxide ion is generated and consequently higher $\mathrm{pH}$ values are expected. Electrical conductivity (EC) rapidly increased during the first two days, decreased during the next three days and plateaued after that (Fig. S3). The rapid EC increase was related to the rapid leaching of anions (i.e., sulfate and orthophosphate) from the soil after receiving a dilute and sterile mix of 10:90 feedlot runoff and DI water.

\subsection{Fate of antibiotics}

Fractional $\left(\mathrm{C}_{\mathrm{i}} / \mathrm{C}_{0}\right)$ breakthrough curves (BTCs) of the three antibiotics are shown in Fig. 1 and could be related to the chemical properties of the antibiotics. Peak breakthrough occurred earlier for the bromide (Fig. S4) than for the antibiotics (Fig. 1). The appearance and disappearance of the three antibiotics in the effluent and from the two sampling ports was slow, the shape of the BTCs was asymmetric with long tailing (Fig. 1), characteristic of desorption 

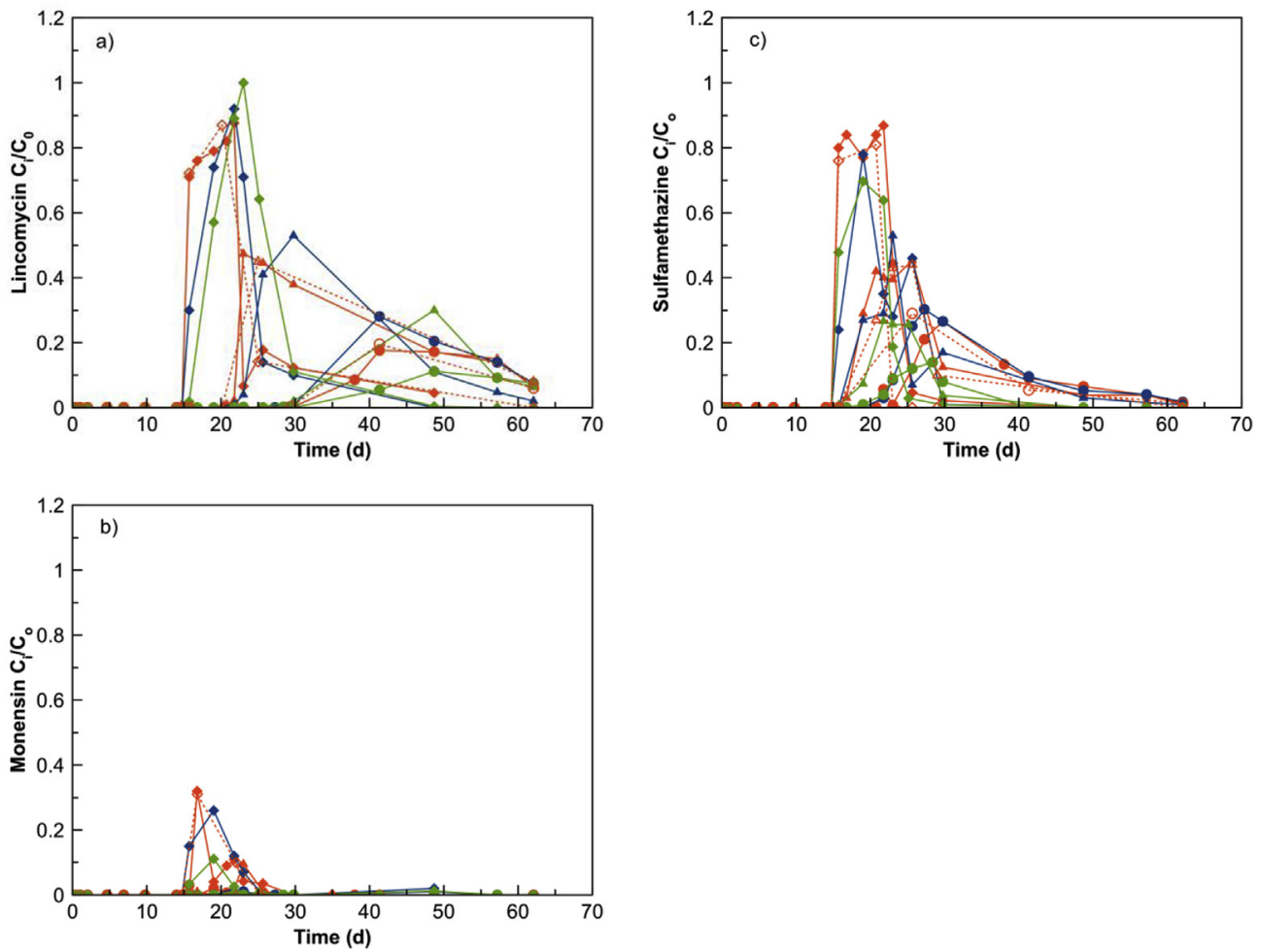

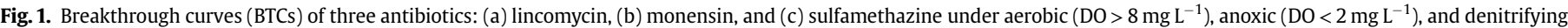

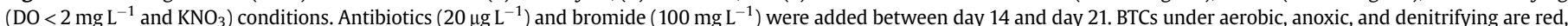

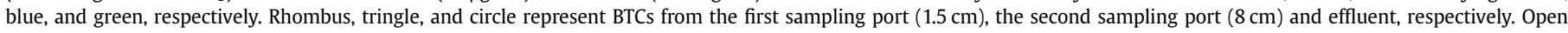

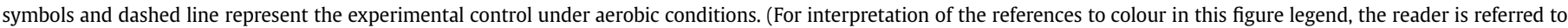
the Web version of this article.)

and dispersion. Among the three antibiotics, monensin was not detected in any samples from the column effluent and only detected in pore water samples collected in the upper portion of the columns regardless of the environmental (aerobic vs. anoxic vs. denitrifying) conditions. Lincomycin and sulfamethazine were detected in the effluent throughout the study, but effluent concentrations decreased during transport through the soil columns (Fig. 1).

Mass recovery (the ratio of the mass recovered after the two sampling ports and in the effluent compared to the mass injected) decreased with depth with lincomycin and monensin showed the highest and the lowest mass recovery, respectively (Table S6). Under aerobic and anoxic conditions, lincomycin was completely recovered ( $100 \%$ of injected concentration) in the upper half of each column (up to $8 \mathrm{~cm}$ ), and decreased, in the lower half of each column, to $68 \%$ and $53 \%$ under anoxic and aerobic conditions, respectively. Under denitrifying conditions, mass recovery of lincomycin decreased from $100 \%$ (upper $1.5 \mathrm{~cm}$ ) to $68 \%$ (upper $8 \mathrm{~cm}$ ) to $28 \%$ (lower half of the column) (Table S6). Recovery of sulfamethazine and lincomycin was lower under denitrifying conditions than under aerobic and anoxic conditions. This behavior may be linked to the change in microbial communities observed under denitrifying conditions, resulting in an increasing removal of the two antibiotics and on a significant impact on the nitrate/nitrite cycle. Bertelkamp et al. (2015) investigating the fate of twenty organic micropollutants under anoxic conditions, observed long half-live, and expected higher removal for lincomycin, and consequently lower mass recovery, under more reducing conditions and in the presence of a longer residence time. Sulfamethazine showed a similar behavior, but slightly lower mass recovery ( $60 \%$ under aerobic and anoxic conditions) compared to lincomycin. Park and Huwe (2016) investigating the effect of solution $\mathrm{pH}$ and soil structure on transport of sulfonamide compounds using soil columns, achieved $67-85 \%$ recovery of sulfamethazine under aerobic conditions. Limited mass recovery of monensin was observed throughout the study. In the upper $1.5 \mathrm{~cm}$, mass recovery ranged between $22 \%$ under anoxic conditions to 8\% under denitrifying conditions (Table S6). Concentrations of the three antibiotics showed a similar behavior compared with the results obtained under aerobic sterile conditions (Fig. 1), suggested that biodegradation played a minor role.

Monensin's hydrophobic nature (log $\mathrm{K}_{\mathrm{ow}}$ of 5.43) contributed to its observed low mobility (Table S1); it was only observed within the top $1.5 \mathrm{~cm}$ of the column with low to no recovery in the effluent. Limited movement of monensin was observed in a field study conducted by Carlson and Mabury (2006). Strong sorption of monensin to soils and sediments is expected due to its hydrophobicity. Sassman and Lee (2007) observed high sorption of monensin on different agricultural soils. These results are in accordance to previous studies on monensin disappearance in soils (Carlson and Mabury, 2006; Sassman and Lee, 2007; Watanabe et al., 2008), suggesting that monensin would degrade primarily in agricultural soils before moving to groundwater. In addition, at high values of $\mathrm{pH}$, monensin is neutralized by chelating with cations and forms complexes which are more likely to increase the $\log \mathrm{K}_{\mathrm{ow}}$ of the ionized monensin, and therefore its hydrophobicity and its sorption capacity (ElSayed and Prasher, 2014). On the other hand, lincomycin and sulfamethazine are classified as hydrophilic ( $\log \mathrm{K}_{\mathrm{ow}}$ of 0.29 and 0.76 , respectively) and thus were expected to migrate through the soil columns. In addition to hydrophobicity, pH likely also affects mobility. The pKa values of lincomycin, monensin, and sulfamethazine are 7.6, 4.2, and 7.65, respectively (Table S1). Effluents from the soil columns showed $\mathrm{pH}$ values ranging between 7 and 9 , greater than pKa of selected antibiotics, suggesting enhanced 
movement of lincomycin and sulfamethazine. The mobility of lincomycin and sulfamethazine is enhanced by $\mathrm{pH}$ values above 7.5. In particular, the increased mobility of sulfamethazine at high $\mathrm{pH}$ is due to increased presence of anionic sulfamethazine (speciation of approximately 65\%) and consequently sorption of sulfamethazine to negatively charges mineral and organic matter surfaces is expected to decrease (Boxall et al., 2002; Chu et al., 2013; Gao and Pedersen, 2005; Kahle and Stamm, 2007; Park and Huwe, 2016; Thiele-Bruhn and Aust, 2004). Relatively low values of the adsorption coefficient were observed during batch investigations supporting the mobility of sulfamethazine in soil (Chu et al., 2013; Doretto et al., 2014). Similarly, to sulfamethazine, enhanced movement and consequently reduced sorption of lincomycin occurs while pH solution increased. Wang et al. (2009) observed a reduced sorption of lincomycin while $\mathrm{pH}$ solution increased.

\subsection{Effect of antibiotics to $N$ transformation}

Feed water was intentionally spiked with nitrate in the denitrifying treatment. Thus, very little nitrate or nitrite was observed in the effluent of aerobic and anoxic columns (Fig. 2). No nitrate/ nitrite transformation was observed in the feed water reservoir during the study. During the acclimation period (no antibiotics added to the feed water), nitrate increased from 10 to $75 \mathrm{mg} \mathrm{L}^{-1}$ in the effluent, while nitrite ranged between 5 and $25 \mathrm{mg} \mathrm{L}^{-1}$, during the same period (Fig. 2). During acclimation, stable nitrate concentrations were observed at all sampling intervals and overall decreased by roughly half as nitrate-amended feed water moved through the soil column. Nitrite was not observed in the upper portion of the column, but a small amount was consistently detected in the effluent during acclimation. After the injection of the three antibiotics in the feed water, nitrate concentrations decreased quickly in the first two sampling ports and eventually decreased below the analytical detection limit after 6 days of injection (Fig. 2a). In parallel, nitrite concentrations began to increase and reached a maximum of 60 and $30 \mathrm{mg} \mathrm{L}^{-1}$ at the end of the spike at the first and second sampling port, respectively (Fig. 2b). After discontinuing influent antibiotic dosing, nitrate concentrations increased and nitrite concentrations decreased to acclimation period levels (Fig. 2). A test to compare individual versus mixed antibiotic effect in feed water was used to evaluate the effect to evaluate the effect to microbial respiration (Fig. 3). Among the three antibiotics, monensin alone had a negligible effect while individually added sulfamethazine and even more lincomycin affected the nitrate/nitrite transformation (Fig. 3). In particular, sulfamethazine and lincomycin individually added to the feed water, were able to replicate the impact of the antibiotics' mix on the nitrate/nitrite transformation in the lower half of the columns (Fig. 3b and c). The impact of these two individually added antibiotics was less pronounced in the upper portion of the column (Fig. 3a). In fact, while nitrate was completely degraded during the injection of the antibiotics' mix, a $60 \%$ reduction of nitrate was achieved in the upper portion when sulfamethazine and lincomycin were individually added.

The nitrate/nitrite transformation observed throughout the study can be linked to the permanent changes in microbial communities occurred in the upper $1.5 \mathrm{~cm}$, while temporary changes occurred throughout the column (Fig. 4, S5). In the upper $1.5 \mathrm{~cm}$, Actinobacteria (-4\%) and Alphaproteobacteria (- 7\%) progressively decreased while Sphingobacteriia $(+4 \%)$ progressively increased (Fig. S5). This behavior - long term changes in top $1.5 \mathrm{~cm}$ vs. temporary changes in the lower portion - was likely linked to higher exposure to antibiotics in the upper portion of the column compared to the lower portion. Among the three antibiotics, lincomycin had the most similar effect on the microbial
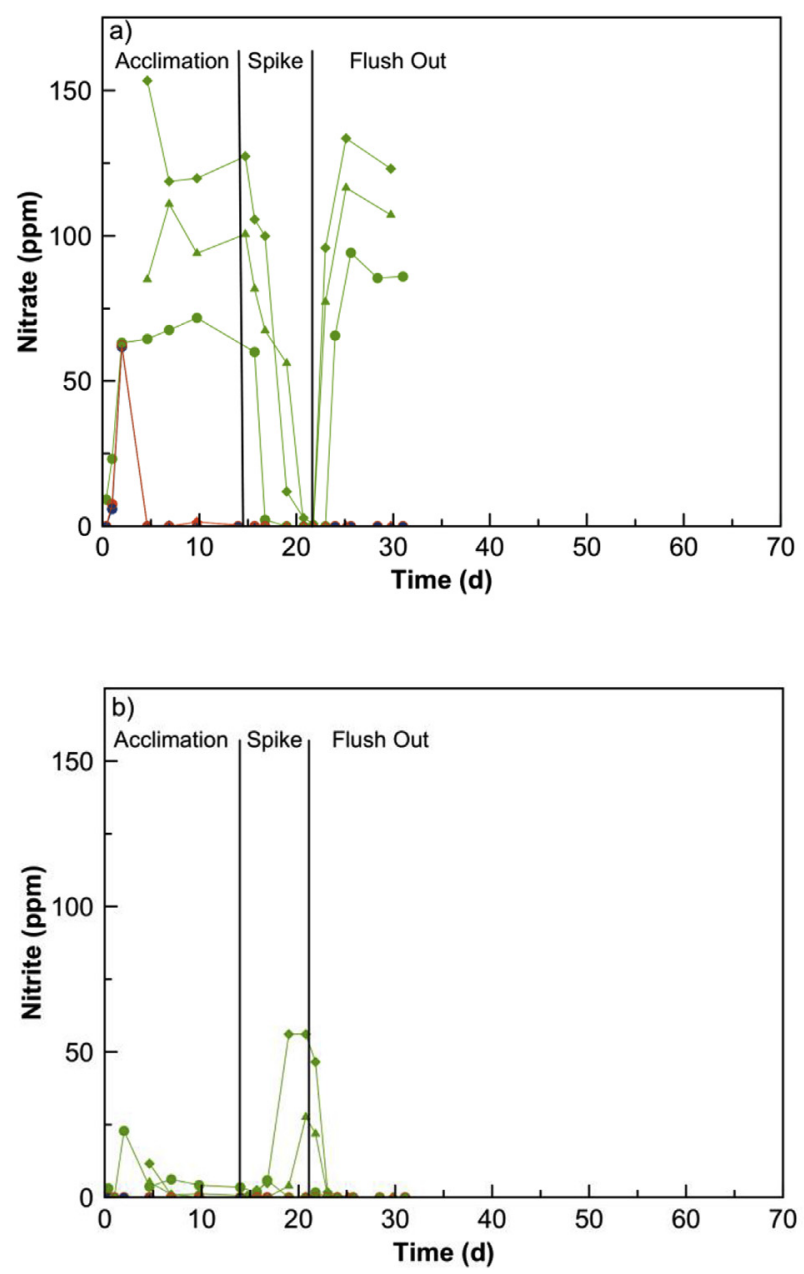

Fig. 2. Impact of selected antibiotics on (a) nitrate and (b) nitrite under aerobic $\left(\mathrm{DO}>8 \mathrm{mg} \mathrm{L}^{-1}\right)$, anoxic $\left(\mathrm{DO}<2 \mathrm{mg} \mathrm{L}^{-1}\right)$, and denitrifying $\left(\mathrm{DO}<2 \mathrm{mg} \mathrm{L}^{-1}\right.$ and $\left.\mathrm{KNO}_{3}\right)$ conditions. During the "Acclimation", the column received an autoclaved mixture of feedlot runoff (10\%) and deionized water (90\%); during the "Spike", $20 \mu \mathrm{g} \mathrm{L}^{-1} \mathrm{mix}$ of lincomycin, monensin, and sulfamethazine were added; during the "Flush Out" the injection of the mix of antibiotics was suspended. Breakthrough curves (BTCs) under aerobic, anoxic, and denitrifying are red, blue, and green, respectively. Rhombus, tringle, and circle represent BTCs from the first sampling port $(1.5 \mathrm{~cm})$, the second sampling port $(8 \mathrm{~cm})$ and effluent, respectively. Open symbols and dashed line represent the experimental control under aerobic conditions. (For interpretation of the references to colour in this figure legend, the reader is referred to the Web version of this article.)

communities throughout the columns compared to the antibiotic mix (Fig. S6).

Results from this study confirmed that sulfamethazine affects nitrate transformation to nitrite, the first step of the denitrification process (Ahmad et al., 2014; Hou et al., 2014; Yin et al., 2017). Ahmad et al. (2014) investigated the inhibitory effect of antibiotics on denitrification using microcosms experiments and observed enhanced removal of nitrate and production of nitrite under anaerobic conditions in the presence of sulfamethazine. At relatively low concentration $\left(0.01 \mathrm{mg} \mathrm{L}^{-1}\right)$, sulfamethazine decreased nitrate reduction rates, while higher concentrations $\left(0.1-1 \mathrm{mg} \mathrm{L}^{-1}\right)$ stimulated nitrate reduction to nitrite (Ahmad et al., 2014). Similarly to Yin (Yin et al., 2017), multiple antibiotics, including sulfamethazine, enhanced nitrate conversion to nitrite. Sun (Sun et al., 2017) investigating the role of excessive anthropogenic nitrate input in the anoxic dissipation of soil antibiotics, including two sulfa-compounds/ARGs observed a sharp decline in nitrate during the first five days of incubation and an increase in the production 

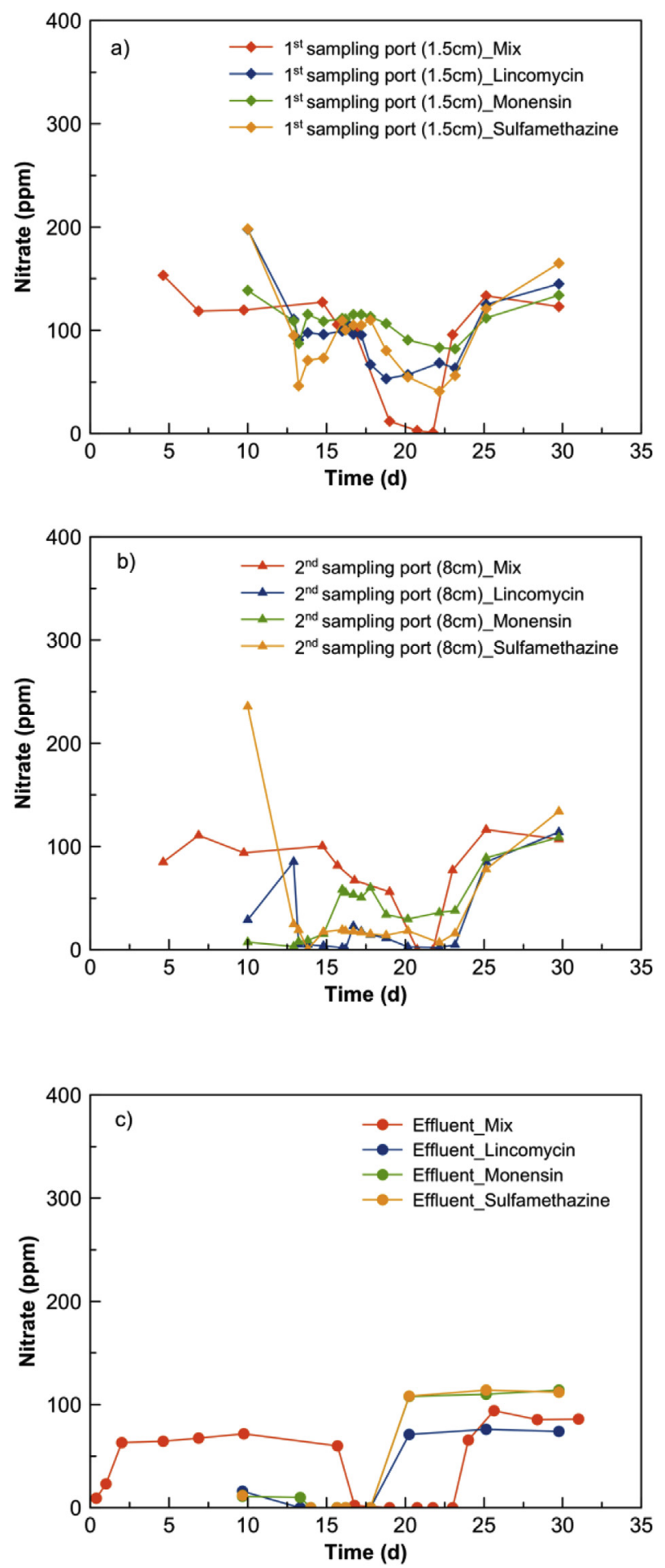

Fig. 3. Impact of selected antibiotics on nitrate under denitrifying ( $\mathrm{DO}<2 \mathrm{mg} \mathrm{L}^{-1}$ and $\mathrm{KNO}_{3}$ ) conditions after (a) the first sampling port $(1.5 \mathrm{~cm})$, (b) the second sampling port $(8 \mathrm{~cm})$ and (c) effluent, respectively. During the "Acclimation", the column received an autoclaved mixture of feedlot runoff $(10 \%)$ and deionized water (90\%); during the "Spike", $20 \mu \mathrm{g} \mathrm{L}^{-1}$ mix of lincomycin, monensin, and sulfamethazine were added; during the "Flush Out" the injection of the mix of antibiotics was suspended. "Mix" refers to the spike solution containing a mixture of lincomycin, monensin, and sulfamethazine. "Licomycin", "monensin", and "sulfamethazine" refer to the spike of individual antibiotics.

rate of nitrite during the first 10 days. A recent reported study on the effect of monensin residues to nitrogen transformation in soil showed no effect of monensin on nitrification rates (Konopka et al., 2015). To our knowledge this was the first study reporting the effect lincomycin on microbial respiration and nitrate-nitrogen reduction in a soil system.

\subsection{Antibiotic effect to microbial communities - aerobic and anoxic conditions}

Microbial community compositions in the column effluent were sampled throughout the course of the experiment, allowing temporal characterization under three respiratory conditions. There were $1,384,820$ sequences that passed quality control, with a mean of 38,467 reads per-library (range 26,026-45,421).

In the untreated control soil used as packing material for the different columns, Proteobacteria (36.1\%), Actinobacteria (18.8\%), Bacteroidetes (15.7\%), and Chloroflexi (12.1\%) were the predominant phyla, while none of the other phyla were detected at levels greater than 5\% (Fig. 4 and S6). After 14 days of acclimatization with sterilized runoff water, phylum-level distributions remained similar for the aerobic and anoxic columns, with only minor decrease in Protobacteria (28 vs 33\%) and increase in Firmicutes (5 vs $9 \%$ ) in the surface compared to (bottom $-16 \mathrm{~cm}$ ) soil samples. Shannon diversity increased over the 14-day treatment with the autoclaved runoff used for acclimatization (Table S7). No phylumlevel changes were observed in response to mixed antibiotic spike exposure, in either the aerobic or anoxic columns. Addition of the antibiotic mixture had only a minor impact on Shannon diversity in these two columns, with an increase of $0.02,0.06,0.01$ and 0.07 in the aerobic top, aerobic bottom, anaerobic top, and anaerobic bottom samples, respectively (Table S7).

The top ten most frequently occurring class level taxonomic assignments covered between 68 and $75 \%$ of all reads in each sample. Subtle but temporally stable differences were observed in class level distribution between the top and bottom of the aerobic column, with a slightly smaller proportion of bottom samples being assigned to Gammaproteobacteria (Fig. 4, S6). This group of bacteria contains a number of important fecal indicator bacteria and human pathogens. The facultative nature of this group explains the differences observed between the top and bottom of the column. No change was observed in class level Gammaproteobacteria distribution following the seven day three-drug spike, however a small decrease was observed following the 33-day flush (Fig. 4). Overall the seven-day mixed antibiotic exposure changed the distribution of bacteria within the top 10 classes (Fig. 4). Following antibiotic discontinuation and flushing, the communities changed again, with pre-spike and post-flush communities more closely resembling each other compared to those of the post-spike (Fig. 4, S6).

OTU assignments (97\%) reveal patterns similar to those seen at the class level, with a clear change in response to the antibiotic mixture, and the pre-spike and post-flush samples more closely resembling each other than the post exposure samples. Across all samples, the top ten OTUs represented less than ten percent of the total reads for each sample (8.3-9.3\%). OTUs assigned to Gemmatimonadetes dominated all aerobic and anoxic samples except for the anoxic 21-day post-spike sample, in which the most frequently occurring OTUs belonged to actinobacteria. Classes represented in the top 10 OTUs, but not seen with the top 10 class-level taxonomic assignments were Deinococcus, Epsilonproteobacteria, and Flavobacteria.

\subsection{Antibiotic effect to microbial communities - denitrifying conditions}

Proteobacteria (28.6-41.9\%), Actinobacteria (7.7-17.6\%), 

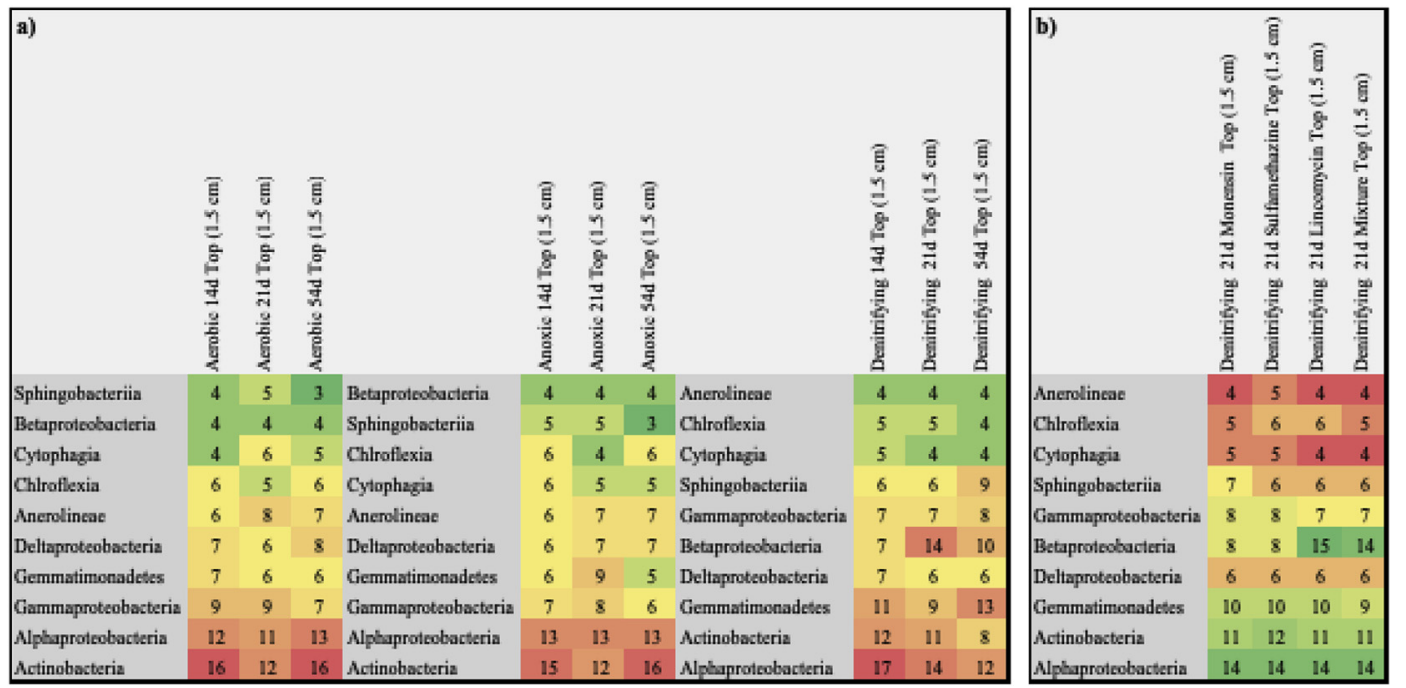

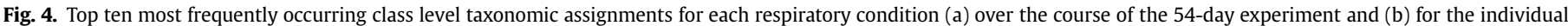

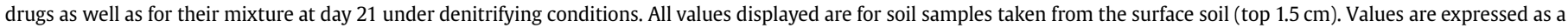

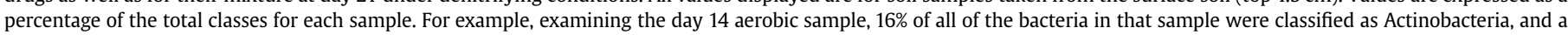

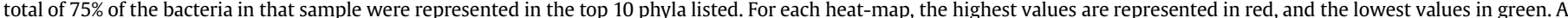

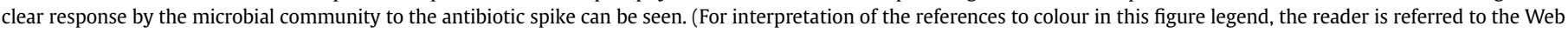
version of this article.)

Bacteroidetes (8.4-20.0\%), Chloroflexi (11.2-15.5\%), and Gemmatimonadates (7.4-13.2\%) were the predominant phyla under denitrifying conditions (Fig. S5). The phylum-level communities in the control soil after 14 days of acclimatization with autoclaved runoff under denitrifying conditions had the same phyla as aerobic and anoxic columns, but had proportionately more sequences assigned to proteobacteria in both the top and bottom of the column compared to the other two respiratory conditions. Under denitrifying conditions, permanent changes in microbial communities occurred in the upper $1.5 \mathrm{~cm}$, while temporary changes occurred throughout the column (Fig. 4, S6).

The class-level taxonomic composition of the denitrified column was identical throughout the incubation to that observed for the aerobic and anoxic columns, however the distribution of sequences was different (Fig. 4). The top ten most frequently occurring class level taxonomic assignments covered between 70 and $81 \%$ of all reads in the samples incubated under denitrifying conditions, with Alphaproteobacteria assignments being the most frequent in the top $1.5 \mathrm{~cm}$ regardless of sample time (Fig. 4). Betaproteobacteria assignments doubled in response to the spike, indicating the ability of members of this group to flourish in the presence of the 3-drug spike. Betaproteobacteria numbers dropped following the flush. Post-flush, Alphaproteobacteria numbers were lower compared to pre-spike (12 vs 17\%), while Sphingobacteria, Gemmatimonadetes, Gamma-, Beta- and Deltaproteobacteria were higher (Fig. S5). Comparing the individual antibiotic spikes to the mixture of three antibiotics, lincomycin had the most similar effect on the microbial communities throughout the columns compared to the antibiotic mix (Fig. S6). Other available studies confirmed that lincomycin similarly impacts the soil microbial communities (Čermák et al., 2008; Grenni et al., 2017).

The denitrifying bacteria are metabolically and taxonomically diverse, and a number of genera have been identified containing denitrifying members (Zumft, 1997). Looking at analysis focused on just these genera, and acknowledging that not every member of a genus is a denitrifier, we observed a shift in response to the threedrug spike. Cytophaga was the most frequently assigned genus in the pre-spike samples, compared to Thiobacillus and Flavobacterium in the post-flush samples (Fig. 5). Cytophaga is a common heterotrophic gram negative gliding soil bacteria in the phylum Bacteroidetes. Flavobacterium is another gram-negative soil bacteria in the phylum Bacteroidetes, and it is not surprising that these two genera likely occupy a similar niche, with the Flavobacterium proliferating in place of the Cytophaga following the spike. Thiobacillus is a member of the Betaproteobacteria. This class doubled in the post-spike sample compared to pre-spike, however Thiobacillus dropped slightly in post-spike samples (from $1 \%$ to $0.87 \%$ ), and then appears to have grown during the post-spike flush (1.74\%) (Fig. 5). Thus the class-level proliferation of Betaproteobacteria cannot be attributed to Thiobacillus. At all three time points, there were between 10 and $12 \%$ of the sequences assigned to these potential denitrifies.

Overlaying the sequencing results, the nitrate and nitrite results it appears that antibiotic exposure did not eliminate the denitrifying bacteria, and that function was restored once the drug spike was flushed from the column. As with any sequencing data of this type, presence of the sequence does not indicate expression of functional genes, which in this instance were not expressed during the exposure. It is possible that the observed bacterial changes explain the stimulation of denitrification reported here, and this hypothesis deserves further study. The current experimental design, however, does not allow us to distinguish correlation and causation for the observed relationships. Instead, it gives us an overview of the temporal dynamics of the microbial communities at multiple depths, in response to respiratory conditions and drug exposure.

Together, these results help characterize the spatial and temporal dynamics of bacterial communities in packed soil columns exposed to antibiotics. The columns were packed with the same source material at the top and bottom of the column, allowing us to confirm that the selective pressures due to depth can enrich for different bacterial communities over time. In general, the changes we observed by depth were minor, with the overall percent of reads assigned at the class-level remaining similar. In addition to impact of depth, our results reveal a clear change in the bacterial communities in response to a seven day mixed antibiotic exposure, including changes in potential denitrifying bacteria.

There are important limitations to the current study. With only a 


\begin{tabular}{|l|c|c|c|}
\hline & $\mathbf{1 4 d}$ & $\mathbf{2 1 d}$ & $\mathbf{5 4 d}$ \\
\hline Cytophaga & 1.70 & 1.35 & 1.47 \\
\hline Sinorhizobium & 1.34 & 1.45 & 1.06 \\
\hline Hyphomicrobium & 0.93 & 1.43 & 1.38 \\
\hline Thiobacillus & 1.00 & 0.87 & 1.74 \\
\hline Flavobacterium & 0.78 & 0.86 & 1.73 \\
\hline Azoarcus & 0.94 & 0.74 & 1.03 \\
Bacillus & 0.70 & 0.55 & 0.53 \\
Sphingobacterium & 0.48 & 0.58 & 0.79 \\
Rhodoplanes & 0.57 & 0.58 & 0.69 \\
\hline Paracoccus & 0.24 & 0.30 & 0.23 \\
Pseudomonas & 0.38 & 0.23 & 0.31 \\
Beggiatoa & 0.20 & 0.24 & 0.21 \\
\hline Nitrobacter & 0.26 & 0.18 & 0.17 \\
Rhodopseudomonas & 0.14 & 0.14 & 0.16 \\
\hline Rhodobacter & 0.08 & 0.09 & 0.20 \\
\hline Azospirillum & 0.14 & 0.14 & 0.11 \\
\hline Zavarzinella & 0.06 & 0.06 & 0.09 \\
\hline Bradyrhizobium & 0.07 & 0.04 & 0.08 \\
\hline Flexibacter & 0.05 & 0.03 & 0.16 \\
\hline Ochrobactrum & 0.03 & 0.02 & 0.01 \\
\hline Alcaligenes & 0.02 & 0.01 & 0.01 \\
\hline Nitrosomonas & 0.01 & 0.00 & 0.01 \\
Moraxella & 0.01 & 0.01 & 0.01 \\
\hline Empedobacter & 0.01 & 0.01 & 0.01 \\
Campylobacter & 0.01 & 0.01 & 0.00 \\
Magnetospirillum & 0.01 & 0.01 & 0.00 \\
\hline Achromobacter & 0.00 & 0.01 & 0.02 \\
\hline Agrobacterium & 0.00 & 0.01 & 0.02 \\
\hline Neisseria & 0.01 & 0.00 & 0.00 \\
\hline & & \\
\hline
\end{tabular}

Fig. 5. Most frequently occurring denitrifying genera under denitrifying conditions over the course of the 54-day experiment. All values displayed are for soil samples taken from the surface soil (top $1.5 \mathrm{~cm}$ ). Values are expressed as a percentage of the total genus-level assignments for each sample. For example, examining the day 14 sample, $1.7 \%$ of all of the bacteria in that sample were classified as Cytophaga, and a total of $10 \%$ of the bacteria in that sample belonged to the denitrifying bacteria listed. For each of the three sample collection times, the highest values are represented in red, and the lowest values in green. (For interpretation of the references to colour in this figure legend, the reader is referred to the Web version of this article.)

single sample for each of the conditions, we cannot draw conclusions beyond the specific samples examined in this study. Also, while our referenced list of denitrifying genera includes the major known groups of denitrifies, it is not comprehensive, and there is variation within genera and species as to the carriage of specific genes associated with denitrification. This experiment does not account for that variation. Nonetheless, this study provides a valuable overview of the dynamics of microbial communities in response to exposure to three commonly used veterinary antibiotics under three respiratory conditions, at three depths, over 54 days. The current study design did allow for comparison of the potential impacts of individual drug components following exposure, revealing lincomycin as the primary driver of the community changes resulting from the mixture.

\section{Conclusions}

Among the three antibiotics, monensin was not detected in the effluent and only detected in pore water samples collected in the upper portion of the columns regardless of the different environmental conditions. Lincomycin and sulfamethazine were detected in the effluent throughout the study, but effluent concentrations decreased during transport through the columns. Under aerobic conditions, similar behavior was observed under sterile and nonsterile conditions, suggesting limited impact of biodegradation. These findings, combined with the results from the sampling ports, decreasing in the antibiotics' concentrations throughout the columns, suggested that sorption represented the predominant removal mechanism.

The nitrogen transformation in the soil was highly impacted by the addition of antibiotics. Denitrification was affected in three antibiotic treatments (mixed antibiotic, lincomycin-alone, and sulfamethazine-alone)—nitrate concentrations rapidly decreased below analytical detection limits, while nitrite concentrations increased. After discontinuation and during antibiotic flush-out, nitrate and nitrite concentrations returned to previous levels. The microbial communities present in the soil were also temporary impacted by the presence of antibiotics. A subtle long-term change in microbial community composition in the upper portion of the columns was observed, while transient changes occurred in the lower portion. These results suggest that veterinary antibiotics could interrupt nitrogen cycling in soils receiving wastewater runoff or manure applications with potential longer-term microbial community changes possible at higher antibiotic concentrations.

\section{Founding source}

Funding for this study was provided by the U.S. Geological Survey (USGS) 104b program, administered through the Nebraska Water Center

\section{Acknowledgments}

We would like to acknowledge Dr. S. Onanong, LC/MS Specialist at the Nebraska Water Center and Dr. M. Vorenhout, University of Amsterdam, The Netherlands, for his invaluable support with theHYPNOS III redox logger.

\section{Appendix A. Supplementary data}

Supplementary data to this article can be found online at https://doi.org/10.1016/j.envpol.2018.11.093.

\section{References}

Ahmad, I., Vithanage, M., Kim, K., Cho, J.S., Lee, Y.H., Joo, Y.K., 2014. Inhibitory effect of veterinary antibiotics on denitrification in groundwater: a microcosm approach. Sci. World J., 879831. https://dx.doi.org/10.1155/2014/879831, 7 pages.

Altschul, S.F., Gish, W., Miller, W., Myers, E.W., Lipman, D.J., 1990. Basic local alignment search tool. J. Mol. Biol. 215, 403-410.

Aust, M.-O., Godlinski, F., Travis, G.R., Hao, X., McAllister, T.A., Leinweber, P., ThieleBruhn, S., 2008. Distribution of sulfamethazine, chlortetracycline and tylosin in manure and soil of Canadian feedlots after subtherapeutic use in cattle. Enviro. Pollut. 156, 1243-1251.

Banerjee, S., D'Angelo, E., 2013. Livestock antibiotic effects on nitrification, 
denitrification, and microbial community composition in soils. Open J. Soil Sci. 3, 203-212.

Bartelt-Hunt, S.L., Snow, D.D., Damon-Powell, T., Miesbach, D., 2011. Occurrence of steroid hormones and antibiotics in shallow groundwater impacted by livestock waste control facilities. J. Contam. Hydrol. 123, 94-103.

Batt, A.L., Snow, D.D., Aga, D.S., 2006. Occurrence of sulfonamide antimicrobials in private wells in Washington County, Idaho, USA. Chemosphere 64, 1963-1971.

Bertelkamp, C., Schoutteten, K., Vanhaecke, L., Bussche, J.V., Callewaert, C., Boon, N., Singhal, N., van der Hoek, J.P., Verliefde, A.R.D., 2015. A laboratory-scale column study comparing organic micropollutant removal and microbial diversity for two soil types. Sci. Total Environ. 536, 632-638.

Boxall, A.B.A., Blackwell, P., Cavallo, R., Kay, P., Tolls, J., 2002. The sorption and transport of a sulphonamide antibiotic in soil systems. Toxicol. Lett. 131.

Brown, K.D., Kulis, J., Thomson, B., Chapman, T.H., Mawhinney, D.B., 2006. Occurrence of antibiotics in hospital, residential, and dairy effluent, municipal wastewater, and the Rio Grande in New Mexico. Sci. Total Environ. 366, $772-783$.

Buochard, D.C., Williams, M.K., Surampalli, R.Y., 1992. Nitrate contamination of groundwater: sources and potential health effects. J. Am. Water Works Assoc. 84, 85-90.

Burkholder, J., Libra, B., Weyer, P., Heathcote, S., Kolpin, D., Thorne, P.S., Wichman, M., 2007. Impacts of waste from concentrated animal feeding operations on water quality. Environ. Health Persp. 115, 308-312.

Carlson, J.C., Mabury, S.A., 2006. Dissipation kinetics and mobility of chlortetracycline, tylosin, and monensin in an agricultural soil in Northumerland County, Ontario, Canada. Environ. Chem. 25, 1-10.

Čermák, L., Kopecký, J., Novotná, J., Omelka, M., Parkhomenko, N., Plháčková, K., Ságová-Marečková, M., 2008. Bacterial communities of two contrasting soils reacted differently to lincomycin treatment. Appl. Soil Ecol. 40, 348-358.

Chee-Sanford, J.C., Mackie, R.I., Koike, S., Krapac, I.G., Lin, Y.-F., Yannarell, A.C., Maxwell, S., Aminov, R.I., 2009. Fate and transport of antibiotic residues and antibiotic resistance genes following land application of manure waste. J. Environ. Qual. 38, 1086-1108.

Chu, B., Goyne, K.W., Anderson, S.H., Lin, C.-H., Lerch, R.N., 2013. Sulfamethazine sorption to soil: vegetative management, $\mathrm{pH}$, and dissolved organic matter effects. J. Environ. Qual. 42, 794-805.

Conkle, J.L., White, J.R., 2012. An initial screening of antibiotic effects on microbial respiration in wetlands soils. J. Environ. Sci. Heal. A 47, 1381-1390.

Costanzo, S.D., Murby, J., Bates, J., 2005. Ecosystem response to antibiotics entering the aquatic environment. Mar. Pollut. Bull. 51, 218-223.

DeVries, S.L., Zhang, P., 2016. Antibiotic and terrestrial nitrogen cycle: a review. Curr. Poll. Rep. 2, 51-67.

DeVries, S.L., Loving, M., Li, X., Zhang, P., 2015. The effect of ultralow-dose antibiotics exposure on soil nitrate and N2O flux. Sci. Rep. 5.

Ding, C., He, J., 2010. Effect of antibiotics in the environment on microbial populations. Appl. Microbiol. Biot. 87, 925-941.

Doretto, K.M., Peruchi, L.M., Rath, S., 2014. Sorption and desorption of sulfadimethoxine, sulfaquinoxaline and sulfamethazine antimicrobials in Brazilian soils. Sci. Total Environ. 476-477, 406-414.

Dowd, S.E., Cllaway, T.R., Wolcott, R.D., Sun, Y., McKeehan, T., Hagevoort, R.G., Edrington, T.S., 2008. Evaluation of the bacterial diversity in the feces of cattle using $16 \mathrm{~S}$ rDNA bacterial tag-encoded FLX amplicon pyrosequencing (bTEFAP). BMC Microbiol. 8, 125.

ElSayed, E.M., Prasher, S.O., 2014. Fate and transport of monensin in the presence of nonionic surfactant Brij35 in soil. Sci. Total Environ. 490, 629-638.

Exner, M.E., Hirsch, A.J., Spalding, R.F., 2014. Nebraska's groundwater legacy: nitrate contamination beneath irrigated cropland. Water Resour. Res. 50, 4474-4489.

Exner, M.E., Spalding, R.F., 1985. Ground-water contamination and well construction in Southeast Nebraska. Ground Water 23, 26-34.

Gao, J., Pedersen, J.A., 2005. Adsorption of sulfonamide antimicrobial agents to clay minerals. Environ. Sci. Techno. 39, 9509-9516.

Grenni, P., Ancona, V., Caracciolo, A.B., 2017. Ecological effects of antibiotics on natural ecosystems:A review. Microchem. J. https://doi.org/10.1016/j.microc. 2017.02.006.

Hepperly, P., Lotter, D., Ulsh, C.Z., Seidel, R., Reider, C., 2009. Compost, manure and synthetic fertilizer influences crop yields, soil properties, nitrate leaching and crop nutrient content. Compost Sci. Util. 17, 117-126.

Hou, L., Yin, G., Liu, M., Zhou, J., Zheng, Y., Gao, J., Zong, H., Yang, Y., Gao, L., Tong, C., 2014. Effects of sulfamethazine on denitrification and the associated N2O release in estuarine and coastal sediments. Environ. Sci. Techno. 49, 326-333.

Ilhan, Z.E., Ong, S.K., Moorman, T.B., 2011. Dissipation of atrazine, enrofloxacin, and sulfamethazine in wood chip bioreactors and impact on denitrification. J. Environ. Qual. 40, 1816-1823.

Jaimes-Correa, J.C., Snow, D.D., Bartelt-Hunt, S.L., 2015. Seasonal occurrence of antibiotics and a beta agonist in an agriculturally-intensive watershed. Environ. Pollut. 205, 87-96.

Kahle, M., Stamm, C., 2007. Sorption of the veterinary antimicrobial sulfathiazole to organic materials of different origin. Environ. Sci. Techno. 41, 132-138.

Konopka, M., Henry, H.A.L., Marti, R., Topp, E., 2015. Multi-year and short-term responses of soil ammonia-oxidizing prokaryotes to zinc bacitracin, monensin, and ivermectin, singly or in combination. Environ. Toxicol. Chem. 34,
$618-625$

Kotzerke, A., Sharma, S., Schauss, K., Heuer, H., Thiele-Bruhn, S., Smalla, K. Wilke, B.M., Schloter, M., 2008. Alterations in soil microbial activity and Ntransformation processes due to sulfadiazine loads in pig-manure. Enviro. Pollut. 153, 315-322.

Laverman, A.M., Cazier, T., Yan, C., Roose-Amsaleg, C., Petit, F., Garnier, J., Berthe, T. 2015. Exposure to vancomycin causes a shift in the microbial community structure without affecting nitrate reduction rates in river sediments. Environ. Sci. Poll. Res. $1-8$.

Maidak, B.L., Cole, J.R., Lilburn, T.G., Parker, C.T., Saxman, P.R., Farris, R.J. Garrity, G.M., Olsen, G.J., Schmidt, T.M., Tiedje, J.M., 2001. The RDP-II (ribosomal database project). Nucleic Acids Res. 29, 173-174.

Park, J.Y., Huwe, B., 2016. Effect of pH and soil structure on transport of sulfonamide antibiotics in agricultural soils. Environ. Pollut. 213, 561-570.

Parker, D.B., Eisenhauer, D.E., Schulte, D.D., Nienaber, J.A., 1999. Seepage characteristics and hydraulic properties of a feedlot runoff storage pond. T. ASAE 42, 369.

Radl, V., Welzl, G., Albert, A., Wilke, B.M., Amelung, W., Schloter, M., 2015. Drying and rewetting events change the response pattern of nitrifiers but not of denitrifiers to the application of manure containing antibiotic in soil. Appl. Soil Ecol. 95, 99-106.

Roose-Amsaleg, C., Yan, C., Hoang, A.M., Laverman, A.M., 2013. Chronic exposure of river sediments to environmentally relevant levels of tetracycline affects bacterial communities but not denitrification rates. Ecotoxicology 22, 1467-1478.

Rosendahl, I., Siemens, J., Kindler, R., Groeneweg, J., Zimmermann, J., Czerwinski, S., Lamshöft, M., Laabs, V., Wilke, B.M., Vereecken, H., Amelung, W., 2012. Persistence of the fluoroquinolone antibiotic difloxacin in soil and lacking effects on nitrogen turnover. J. Environ. Qual. 41, 1275-1283.

Sassman, S.A., Lee, L.S., 2007. Sorption and degradation in soils of veterinary ionophore antibiotics: monensin and lasalocid. Environ. Toxicol. Chem. 26, 1614-1621.

Sim, W.J., Lee, J.W., Lee, E.S., Shin, S.K., Hwang, S.R., Oh, J.E., 2011. Occurrence and distribution of pharmaceuticals in wastewater from households, livestock farms, hospitals and pharmaceutical manufactures. Chemosphere 82, 179-186.

Snow, D.D., Rus, D.L., Bartelt-Hunt, S.L., 2011. Seasonal variation of surface water veterinary pharmaceutical levels in an agricultural watershed. In: Seasonal Variation of Surface Water Veterinary Pharmaceutical Levels in an Agricultural Watershed, Society of Environmental Toxicologists and Analytical Chemists SETAC North America 32th Annual Meeting. Boston, MA.

Spalding, R.F., Exner, M.E., 1993. Occurrence of nitrate in groundwater - a review. J. Environ. Qual. 22, 392-402.

Sun, M., Ye, M., Liu, K., Schwab, A.P., Manqiang, L., Jiao, J., Feng, Y., Wan, J., Tian, D., Wu, J., Li, H., Hu, F., Jiang, X., 2017. Dynamic interplay between microbial denitrification and antibiotic resistance under enhanced anoxic denitrification condition in soil. Enviro. Pollut. 222, 583-591.

Thiele-Bruhn, S., Aust, M.-O., 2004. Effects of pig slurry on the sorption of sulfonamide antibiotics in soil. Arch. Environ. Contam. Toxicol. 47, 31-39.

Underwood, J.C., Harvey, R.W., Metge, D.W., Repert, D.A., Baumgartner, L.K., Smith, R.L., Roane, T.M., Barber, L.B., 2011. Effect of antimicrobial sulfamethoxazole on groundwater bacterial enrichment. Environ. Sci. Techno. 45 3096-3101.

USDA, 2012. Soil Survey. https://websoilsurvey.sc.egov.usda.gov/App/ WebSoilSurvey.aspx. https://websoilsurvey.sc.egov.usda.gov/App/ WebSoilSurvey.aspx.

Vorenhout, M., van der Geest, H., Harm, G.H., Ellard, R., 2011. An improved datalogger and novel probes for continuous redox measurements in wetlands. Int. J. Environ. Anal. Chem. 91, 801-810.

Wang, C., Ding, Y., Teppen, B.J., Boyd, S.A., Song, C., Hui, L., 2009. Role of interlayer hydration in lincomycin sorption by smectite clays. Environ. Sci. Techno. 43, 6171-6176.

Watanabe, N., Harter, T.H., Bergamaschi, B.A., 2008. Environmental occurrence and shallow ground water detection of the antibiotic monensin from dairy farms. J. Environ. Qual. 37. S-78-S-85.

Wei, R., Ge, F., Huang, S., Chen, M., Wang, R., 2011. Occurrence of veterinary antibiotics in animal wastewater and surface water around farms in Jiangsu Province, China. Chemosphere 82, 1408-1414.

Wei, R., Ge, F., Zhang, L., Hou, X., Cao, Y., Gong, L., Chen, M., Wang, R., Bao, E., 2016. Occurrence of 13 veterinary drugs in animal manure-amended soils in Eastern China. Chemosphere 144, 2377-2383.

Yan, C., Dinh, Q.T., Chevreuil, M., Garnier, J., Roose-Amsaleg, C., Ladbadie, P., Laverman, A.M., 2013. The effect of environmental and therapeutic concentrations of antibiotics on nitrate reduction rates in river sediment. Water Res. 47, 3654-3662.

Yin, G., Hou, L., Liu, M., Zheng, Y., Li, X., Lin, X., Gao, J., Jiang, X., Wang, R., Yu, C.P., 2017. Effects of multiple antibiotics exposure on denitrification process in the Yangtze Estuary sediments. Chemosphere 171, 118-125.

Zhang, Y., Zhang, C., Parker, D.B., Snow, D.D., Zhou, Z., Li, X., 2013. Occurrence of antimicrobials and antimicrobial resistance genes in beef cattle storage ponds and swine treatment lagoons. Sci. Total Environ. 463-464, 631-638.

Zumft, W.G., 1997. Cell biology and molecular basis of denitrification. Microbiol. Mol. Biol. Rev. 61, 533-616. 